\title{
Metadata description of the AMAZON FISH database
}

Céline Jézéquel, Pablo A. Tedesco, Javier A. Maldonado-Ocampo, Saúl Prada-Pedreros, Hernán Ortega, Max Hildalgo, Koen Martens, Aaike De Wever, Jansen Zuanon, Gislene Torrente-Vilara, Leandro M. Sousa, Tommaso Guiarrizzo, Jonathan Valdiviezo, Jaime Sarmiento, Mabel Maldonado, Fernando M. Carvajal-Vallejos, Takayuki Yunoki, Carlos Donascimiento, Edwin Agudelo, José Iván Mojica, Raúl Ríos Herrera, Francisco Villa \& Thierry Oberdorff
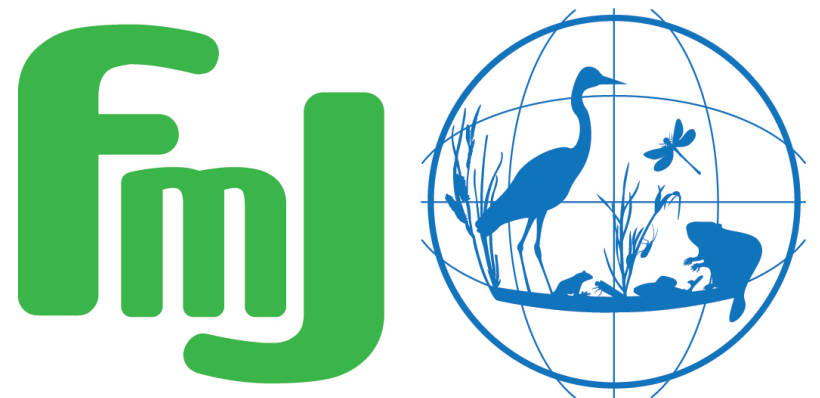

Freshwater Metadata Journal 



\title{
Metadata description of the AMAZON FISH database
}

\author{
Céline Jézéquel ${ }^{1}$, Pablo A. Tedesco ${ }^{1}$, Javier A. Maldonado-Ocampo ${ }^{2}$, Saúl \\ Prada-Pedreros ${ }^{2}$, Hernán Ortega ${ }^{3}$, Max Hildalgo ${ }^{3}$, Koen Martens ${ }^{4}$, Aaike De Wever ${ }^{4}$, \\ Jansen Zuanon ${ }^{5}$, Gislene Torrente-Vilara ${ }^{6}$, Leandro M. Sousa ${ }^{7}$, Tommaso Guiarrizzo ${ }^{7}$, \\ Jonathan Valdiviezo ${ }^{17}$, Jaime Sarmiento ${ }^{9}$, Mabel Maldonado ${ }^{10}$, Fernando $M$. \\ Carvajal-Vallejos ${ }^{10}$, Takayuki Yunoki ${ }^{11}$, Carlos Donascimiento ${ }^{12}$, Edwin Agudelo ${ }^{13}$, José \\ Iván Mojica ${ }^{14}$, Raúl Ríos Herrera ${ }^{15}$, Francisco Villa ${ }^{16}$ \& Thierry Oberdorff ${ }^{1}$ \\ 1 Institut de Recherche pour le Développement (IRD), UMR EDB, Toulouse, France; corresponding author: celine.jezequel@ird.fr \\ 2 Pontificia Universidad Javeriana, Bogota, Colombia \\ 3 Universidad Nacional Mayor de San Marcos, Universidad del Perú, Decana de América, Museo de Historia, Lima, Peru \\ 4 Royal Belgian Institute of Natural Sciences (RBINS), Brussels, Belgium \\ 5 Instituto Nacional de Pesquisas da Amazônia (INPA), Manaus, Brasil \\ 6 Universidade Federal de São Paulo (UNIFESP), São Paulo, Brasil \\ 7 Universidade Federal do Pará (UFPA), Pará, Brasil \\ 8 Museo Ecuatoriano de Ciencias Naturales (MECN), Quito, Equador \\ 9 Museo Nacional de Historia Natural, Instituto de Ecología, La Paz, Bolivia \\ 10 Universidad Mayor de San Simón, Cochabamba, Bolivia \\ 11 Universidad Autónoma del Beni, Centro de Investigación de Recursos Acuáticos, Trinidad, Bolivia \\ 12 Instituto Alexander von Humboldt (IAvHP), Bogota, Colombia \\ 13 Instituto Amazónico de Investigaciones Científicas SINCHI, Leticia, Colombia \\ 14 Instituto de Ciencias Naturales, Universidad Nacional de Colombia (ICNMHN), Bogota, Colombia \\ 15 Instituto para la Investigación y la Preservación del Patrimonio Cultural y Natural (INCIVA), Cali, Colombia \\ 16 Grupo de Investigación en Zoología, Facultad de Ciencias, Universidad del Tolima, Ibagué, Colombia \\ 17 Instituto Nacional De Biodiversidad (INABIO), Quito, Ecuador
}

Please cite this paper as follows: Jézéquel, C., Tedesco, P. A., Maldonado-Ocampo, J. A., Prada-Pedreros, S., Ortega, H., Hildalgo, M., Martens, K., De Wever, A., Zuanon, J., Torrente-Vilara, G., Sousa, L. M., Guiarrizzo, T., Valdiviezo, J., Sarmiento, J., Maldonado, M., Carvajal-Vallejos, F. M., Yunoki, T., Donascimiento, C., Agudelo, E., Mojica, J. I., Herrera, R. R., Villa, F. \& Oberdorff, T., 2019. Metadata description of the AMAZON FISH database. Freshwater Metadata Journal 43: 1-9. https://doi.org/10.15504/fmj.2019.43

Received: 2017-12-21 / Published: 2019-03-18

\section{Keywords}

fish, database, Amazon basin, Amazon river, database description

\section{Short description of the dataset/summary}

The title "AMAZON FISH database" is a working title for the Amazonian Freshwater Fish Biodiversity database that was constructed in the framework of the AMAZON FISH (ERANetLAC/DCC-0210) project.

In order to construct the AMAZON FISH database, which aims to become a high quality freshwater fish biodiversity 
database covering the entire Amazon drainage basin, data from a wide range of sources were compiled in a central database. The content of this database can be considered as a collection of curated datasets or dataset exports (as the database only covers the Amazon basin, while source datasets may cover larger areas).

These datasets are of different nature and include:

A. Information extracted from the literature (published articles, books, gray literature).

B. Data available from museums/collections and universities.

C. Data held or compiled by project partners (e.g. at country level). Some of these have previously been published through the Global Biodiversity Information Facility (GBIF) network, while others will be released in the framework of AMAZON FISH.

D. Data extracted from online databases such as GBIF, FishNet, SpeciesLink and IABIN.

E. New data obtained during (a) sampling campaign(s) in the framework of the project.

At this stage (December 2018), the database already provides a comprehensive overview of the fish diversity and distribution in the Amazon basin, with over 305.000 occurrence records from 123 sources (mostly covering B, C \& D). After the project formally ends, it will still be updated by including new data from the project partners (C), from literature references $(\mathrm{A})$ and potentially by including data from new sampling campaigns (E) to areas for which we identified a gap in the available data.

Through the integration of these different data sources, the AMAZON FISH database constitutes a unique resource on the Amazon basin, which concentrates the highest freshwater biodiversity on earth. By compiling the knowledge on the spatial distribution of freshwater fishes and addressing the taxonomic and sampling gaps, this database should enable comprehensive analysis and modeling. As such it will answer the essential need for understanding this unique ecosystem that has produced such high freshwater fish diversity.

\section{General information}

dataset entry ID:

name of the dataset:

full name of the dataset:

dataset short name:

type of dataset:

data type:
AF_1

AMAZON FISH database

AMAZON FISH database

species distribution data

point data/observation data

science keywords according to GCMD:

topic:

Biosphere, Biological Classification

ISO topic category according to ISO 19115:

Biota, Environment, Inland Waters

INSPIRE keywords according to GEMET:

own science keywords:

Species distribution

freshwater fish, Amazon river drainage, Amazon basin, occurrence database, species distribution

related project:

AMAZON FISH (ERANet-LAC/DCC-0210)

funding:

ERANet-LAC: Network of the European Union, Latin America and the

Caribbean Countries on Joint Innovation and Research Activities

\section{Technical and administrative specifications}

data format:

others/details: others/specify

PostgreSQL 


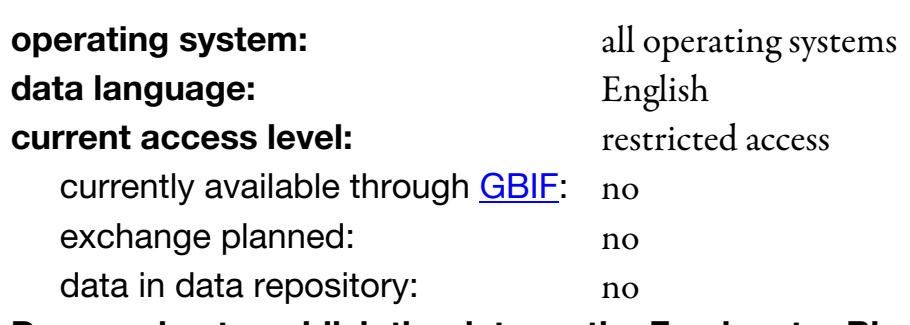

Do you plan to publish the data on the Freshwater Biodiversity Data Portal:

update level:

documentation:

type:

others/details:

language:

contact details:

metadata contact person:

first, last name:

email:

institution:

address:

postal code, city:

country

technical contact person:

first, last name:

email:

institution:

address:

postal code, city:

country:

web address:

scientific contact person:

first, last name:

email: yes

update planned

others/specify

Data Management Plan (https://doi.org/10.6084/m9.figshare.5150716.v1) English

\section{Céline Jézéquel}

celine.jezequel@ird.fr

Institut de Recherche pour le Développement (IRD)

UMR EDB, 118 route de Narbonne

31000 Toulouse

France

Céline Jézéquel

celine.jezequel@ird.fr

Institut de Recherche pour le Développement (IRD)

UMR EDB, 118 route de Narbonne

31000 Toulouse

France

Thierry Oberdorff

thierry.oberdorff@ird.fr

\section{Intellectual property rights and citation}

dataset creator (data compiler):

contact name:

Thierry Oberdorff

contact email:

thierry.oberdorff@ird.fr

contact institution:

Institut de Recherche pour le Développement (IRD), UMR EDB 5174

\section{data contributors to/owners of this dataset:}

number:

data contributor/owner 1 :

contact name:

contact email:

contact institute: multiple

20

\section{Thierry Oberdorff}

thierry.oberdorff@ird.fr

Institut de Recherche pour le Développement (IRD), UMR

criteria for using this part of the dataset:

The dataset needs to be requested from dataset creator with specific conditions of use. 


\title{
data contributor/owner 2:
}

contact name:

contact email:

contact institute:
Javier A. Maldonado-Ocampo

maldonadoj@javeriana.edu.co

Pontificia Universidad Javeriana, Unidad de Ecología y Sistemática (UNESIS)

criteria for using this part of the dataset:

The dataset needs to be requested from dataset creator with specific conditions of use.

\section{data contributor/owner 3:}

contact name:

contact email:

Hernán Ortega

contact institute:

hortega@gmail.com

criteria for using this part of the dataset:

The dataset needs to be requested from dataset creator with specific conditions of use.

\section{data contributor/owner 4:}

contact name:

contact email:

Aaike De Wever

contact institute:

aaike.dewever@naturalsciences.be

criteria for using this part of the dataset:

Royal Belgian Institute of Natural Sciences (RBINS)

The dataset needs to be requested from dataset creator with specific conditions of use.

comments:

No direct data contributions included. Contribution mainly consisted of technical advise during database construction.

\section{data contributor/owner 5:}

contact name:

Jansen Zuanon

contact email:

jzuanon3@gmail.com

contact institute:

criteria for using this part of the dataset:

Instituto Nacional de Pesquisas da Amazônia (INPA)

The dataset needs to be requested from dataset creator with specific conditions of use.

\section{data contributor/owner 6:}
contact name:
Gislene Torrente-Vilara
contact email:
gtvilara@gmail.com
contact institute:
Universidade Federal de São Paulo (UNIFESP)
criteria for using this part of the dataset:

The dataset needs to be requested from dataset creator with specific conditions of use.

data contributor/owner 7:
contact name:
Leandro M. Sousa
contact email:
m.sousa@gmail.com
contact institute:
Universidade Federal do Pará (UFPA)

criteria for using this part of the dataset:

The dataset needs to be requested from dataset creator with specific conditions of use.

\section{data contributor/owner 8:}

\author{
contact name: \\ contact email: \\ Jonathan Valdiviezo \\ contact institute: \\ jonathan.valdiviezo@biodiversidad.gob.ec \\ criteria for using this part of the dataset: \\ Instituto Nacional De Biodiversidad (INABIO) - Ecuador
}

The dataset needs to be requested from dataset creator with specific conditions of use. 


\section{data contributor/owner 9:}

contact name:

contact email:

contact institute:
Jaime Sarmiento

jsarmientotavel@gmail.com

Museo Nacional de Historia Natural, Instituto de Ecología

criteria for using this part of the dataset:

The dataset needs to be requested from dataset creator with specific conditions of use.

\section{data contributor/owner 10:}

contact name:

contact email:

contact institute:
Mabel Maldonado

mabelmaldonado.m@fcyt.umss.edu.bo

Universidad Mayor de San Simón, Unidad de Limnología y Recursos Acuáticos

(ULRA)

criteria for using this part of the dataset:

The dataset needs to be requested from dataset creator with specific conditions of use.

data contributor/owner 11:

contact name:

Takayuki Yunoki

contact email:

takayukiyunoki@yahoo.com

contact institute:

Universidad Autónoma del Beni, Centro de Investigación de Recursos Acuáticos criteria for using this part of the dataset:

The dataset needs to be requested from dataset creator with specific conditions of use.

\section{data contributor/owner 12:}

contact name:

Carlos Donascimiento

contact email:

cdonascimiento@humboldt.org.co

contact institute:

Instituto Alexander von Humboldt (IAvHP)

criteria for using this part of the dataset:

The dataset needs to be requested from dataset creator with specific conditions of use.

data contributor/owner 13:

contact name:

contact email:

contact institute:

criteria for using this part of the dataset:

Edwin Agudelo

eagudelo@sinchi.org.co

Instituto Amazónico de Investigaciones Científicas SINCHI (CIACOL)

The dataset needs to be requested from dataset creator with specific conditions of use.

data contributor/owner 14:

contact name:

contact email:

contact institute:

criteria for using this part of the dataset:

The dataset needs to be requested from dataset creator with specific conditions of use.

\section{data contributor/owner 15:}

contact name:

contact email:

contact institute:

criteria for using this part of the dataset:

Raúl Ríos Herrera

raulriosh@gmail.com

Instituto para la Investigación y la Preservación del Patrimonio Cultural y Natu

The dataset needs to be requested from dataset creator with specific conditions of use. 


\section{data contributor/owner 16:}

contact name:

Francisco A. Villa-Navarro

contact email:

favilla@ut.edu.co

contact institute:

Universidad del Tolima (CZUT-IC)

criteria for using this part of the dataset:

The dataset needs to be requested from dataset creator with specific conditions of use.

\section{data contributor/owner 17:}

contact name:

contact email:

Max Hidalgo

contact institute:

mhidalgod@unmsm.edu.pe

UNMSM, Peru

criteria for using this part of the dataset:

The dataset needs to be requested from dataset creator with specific conditions of use.

\section{data contributor/owner 18:}

contact name:

contact email:

Fernando M. Carvajal-Vallejos

contact institute:

fernando.carvajal@faunagua.org

FAUNAGUA

criteria for using this part of the dataset:

The dataset needs to be requested from dataset creator with specific conditions of use.

data contributor/owner 19:

contact name:

Céline Jézéquel

contact email:

celine.jezequel@ird.fr

contact institute:

IRD

criteria for using this part of the dataset:

The dataset needs to be requested from dataset creator with specific conditions of use.

data contributor/owner 20:

contact name:

Pablo A. Tedesco

contact email:

pablo.tedesco@ird.fr

contact institute:

IRD

criteria for using this part of the dataset:

The dataset needs to be requested from dataset creator with specific conditions of use.

\section{citation of this dataset:}

author(s):

Jézéquel, C., Tedesco, P. A., Maldonado-Ocampo, J. A., Prada-Pedreros, S., Ortega, H., Hildalgo, M., Martens, K., De Wever, A., Zuanon, J.,

Torrente-Vilara, G., Sousa, L. M., Guiarrizzo, T., Valdiviezo, J., Sarmiento, J.,

Maldonado, M., Carvajal-Vallejos, F. M., Yunoki, T., Donascimiento, C.,

Agudelo, E., Mojica, J. I., Herrera, R. R., Villa, F. \& Oberdorff, T.

title and journal (name, number, pages):

The Amazon Fish database: freshwater fish distribution for the entire Amazon drainage

year:

2019

\section{citation of the metadata:}

author(s):

Jézéquel C., Tedesco P. A., Maldonado-Ocampo J. A., Prada-Pedreros S., Ortega H., Hildalgo M., Martens K., De Wever A., Zuanon J., Torrente-Vilara G., Sousa L. M., Guiarrizzo T., Valdiviezo J., Sarmiento J., Maldonado M., Carvajal-Vallejos F. M., Yunoki T., Donascimiento C., Agudelo E., Mojica J. I., Herrera R. R., Villa F. \& Oberdorff T. 
title and journal (name, number, pages):

Metadata description of the AMAZON FISH database. Freshwater Metadata Journal 43: 1-9

year: 2019

doi:

\section{https://doi.org/10.15504/fmj.2019.43}

comments:

The AMAZON FISH database integrates a wide range of datasets from different public and project partners sources, and results from a three years international team effort.

The entire, curated database at the sub-basins scale (modified HydroBASINS dataset) will be documented and released in a data paper that should be submitted during the year 2019. All occurrence records (point scale data) for which we obtained permission for public release will be made available through the AMAZON FISH data online repository or through the Freshwater

Biodiversity Portal (http://data.freshwaterbiodiversity.eu/; which is a member of the Freshwater Information Platform). The release of the occurrence records will be effective three years after the official publication of the data paper, a timeframe considered sufficient to publish the analyses suggested in the initial AMAZON FISH projet. During this embargo period, site scale data may be available on request pending agreement of all partners and with authorship negotiation possible.

The sub-basins scale data paper will include an extensive database description along with a discussion on the database content, gap analysis and database statistics, in parallel with the on-line release of the database at the sub-basins scale.

In addition to the publication of the datasets and database itself, key maps produced during the AMAZON FISH project will be disseminated through the Global Freshwater Biodiversity Atlas (http://atlas.freshwaterbiodiversity.eu/) following the publication of scientific paper(s) describing those results.

\section{General data specifications}

regional coverage of the dataset: spatial extent of the dataset: catchment continents:

South America

\section{spatial extent (bounding coordinates):}

southernmost latitude $\left[^{\circ}\right]$ :

northernmost latitude $\left[^{\circ}\right]$ :

minimum altitude:

0 metres

maximum altitude:

6200 metres

countries:

South America: Bolivia, Brazil, Colombia, Ecuador, Peru, Venezuela

world climatic regions according to Köppen:

Group A: tropical/megathermal climates

freshwater ecoregions of the world (FEOW) according to WWF:

South America: Amazonas Estuary \& Coastal Drainages, Amazonas Guiana

Shield, Amazonas High Andes, Amazonas Lowlands, Guapore - Itenez, Madeira 
ecosystem type:

covered timeframe:
Brazilian Shield, Mamore - Madre de Dios Piedmont, Rio Negro, Tapajos Juruena, Ucayali - Urubamba Piedmont, Western Amazon Piedmont, Xingu rivers, wetlands

$1865-2017$

\section{Site specifications}

$\begin{array}{cl}\text { coordinate system/grid data: } & \text { latitude/longitude, format: DD } \\ & \text { projected, others others: WGS84 } \\ \text { datum (e.g. WGS84): } & \text { WGS84 } \\ \text { grid data available: } & \text { no } \\ \text { number of sites: } & >1000 \\ \text { exact number of sites: } & 22000\end{array}$

\section{Biological data}

biological data origin:

from sampling, AMAZON FISH project ERANetLAC/DCC-0210

comments:

organism group addressed:

Timeframe of the sampled sites: 1865 to 2017.

fish

\section{Sample resolution}

fish:

taxonomic resolution:

level:

species

percentage of species level data: 100

taxonomic coding:

taxalist according to:

reference(s):

FishBase \& California Academy of Sciences-Catalogue of Fishes

Fricke, R., Eschmeyer, W. \& Van der Laan, R. (2018). Catalog of Fishes: Genera, Species, References.

http://researcharchive.calacademy.org/research/ichthyology/catalog/fishcatmai n.asp

Froese, R. \& Pauly, D. (2018). FishBase. World Wide Web electronic publication. www.fishbase.org

sample specifications:

\section{Other specifications}

\section{GIS layers, shape files related to the dataset:}

others/details:

availability of photos:

availability of maps:

quality control procedures: catchments, river-sub-basins

Modified version of HydroBASINS.

no

no

Were any quality control procedures applied to your dataset?

yes

quality control protocols and comments:

To avoid any duplication when integrating data from different sources, all 
duplicates are identified and excluded during import by either verifying unique identifiers for occurrences (or fields that should constitute unique identifiers when considered together; e.g. institute + collection + collection number) or based on sampling details in combination with the geographical coordinates of the data.

Where available, details on provenance, citation, along with a modification/"last updated" timestamp (e.g. only available for GBIF and SpeciesLink) are systematically documented for the retained records.

In addition, during import, each record is systematically checked for reliability and consistency, using the FishBase Consortium database, and the California Academy of Science's Catalog of Fishes, as nomenclature authority files. During the process of building the database, a taxonomic checklist work is achieved to validate all species actually present in the Amazon drainage basin. This important work is done in collaboration with taxonomic experts covering all groups and will be made publicly available through a checklist publication.

\section{Acknowledgements}

This project is supported by the ERANet-Lac programme - Grant number: ERANetLAC/DCC-0210. 